\title{
THE IMPLEMENTATION OF AUTONOMOUS LEARNING IN ENGLISH PRONUNCIATION OF GUIDENCE AND COUNSELING DEPARTMENT'S STUDENTS
}

\author{
Maslakhatin \\ Universitas PGRI Adi Buana Surabaya \\ maslakhatin@unipasby.ac.id \\ Ayong Lianawati \\ Universitas PGRI Adi Buana Surabaya \\ Ayonglianawati17@gmail.com
}

\begin{abstract}
Most Indonesian students have difficulties in learning English pronunciation. Autonomous learning can be as an alternative strategy to help the students in learning pronunciation independently by utilizing Breakingnewsenglish.com. This study aimed to analyze the implementation of autonomous learning in learning pronunciation, the students' response toward autonomous learning, and the impact of autonomous learning on the students' pronunciation achievement. This study used descriptive qualitative method and the subject was Guidance and Counseling department students. The data was collected by observation, field notes, documentation, voice recording, and questionnaire. The result revealed that autonomous learning could be as an alternative strategy in learning pronunciation because the pronunciation performance of the students was significantly increased on the last meeting. They looked more enthusiastic in learning pronunciation autonomously.
\end{abstract}

Keywords: autonomous learning, pronunciation

\section{INTRODUCTION}

Pronunciation has an important role in communicating (Morley, 1991), especially speaking. Gilakjani (2016) also states that pronunciation is one of the crucial components in communication. While, Kristina, at al. (2006) cited in Pratiwi (2010) said that pronunciation requires production, acceptance of sound, and attainment of meaning. It means that if someone pronounces a word or utterance, the sound he produced should be good and understandable, so that the listener will understand what he said. The most important thing in communicating is understandable. It means that what we said can be understood by the listener; it is not a necessity pronouncing an utterance perfectly like a native speaker (Morley, 1991).

According to Burns (2003), there are three components must be reached by an English speaker; they are the speaker produces a sound which is recognized as English (intelligibility), the listener is able to understand the speaker meant from what he said (comprehensibility), the listener is able to understand the aim of what the speaker said (interpretability). For example a speaker says "it is hot today" becomes "it is ho day," this utterance cannot be understood because the sound, 
stressing, and intonation are not clear, so that the listener cannot understand what the speaker said and the listener cannot give response to what the speaker means. Therefore, misunderstanding between the speaker and listener often occurred.

One of the causes of misunderstanding often arises is between Indonesian language and English have different rules and concepts, such as the difference between the spelling and the pronunciation of the words (Riadi, 2013). One of the problems is when students want to pronounce "book," they tend to say "bok" instead of "buk." Besides, English has different concept, such as the plural form of noun. One of the examples is the plural form of the words "book" is "books" and "child" is "children. The different concept here is by adding "s" at the end of the word and the word changes irregularly. Whereas, in Indonesian language, the plural form of the words is merely by repeating the words twice, such as the plural form of the word "anak" is "anak-anak." These differences make Indonesian students; especially those who are from non-English department have difficulties in learning English pronunciation.

Moreover, the learning model; discovery learning and problem based learning which are used on the newest educational curriculum in Indonesia refers to the students' independence (Johar, 2015). It can be said that the learning model used in Indonesia nowadays is student-centered instruction. It means that the students should be more active on their own process learning because their successfulness learning depends on their own hard effort. The teacher here merely is as a motivator and facilitator. Louis (2006) cited in Hayta and Yaprak (2013) argue that a teacher should encourage the students to work or learn autonomously and assist them making a decision in their learning process. Thus, the students will get used to do autonomous learning without relying on the teacher.

Wang (2010) states that autonomous learning is a modern learning theory which is based on constructivism theory, the learning activities in this model focuses on the students (student-centered instruction). Holec (1981) cited in Hayta and Yaprak (2013) define autonomous learning as an ability to involve themselves in their own learning process. In this learning model, the students are responsible for their own learning process and they learn based on their need. This model is very suitable to be implemented in educational system in Indonesia nowadays because Indonesian national qualifications framework curriculum (KKNI) requires the students to be able to learn autonomously.

Dickinson (1993) cited in Hayta and Yaprak (2013) state that an autonomous learning should have the following characteristics:

a. Able to recognize and preserve his or her interest on the topic discussed in the class

b. Able to arrange his or her own learning purpose cooperatively with the teachers

c. Able to choose and use the appropriate learning strategy for his or her own learning purpose

d. Able to manage and revise his or her learning strategy if it is necessary

The development of computer technology had given a significant contribution on the concept of autonomous learning in terms of facilitate an autonomous learner through the number of materials which is able to be learnt autonomously (Godwin-Jones, 2011 cited in Hayta \& Yaprak, 2013). Breakingnewsenglish.com is one of website which provides lots of activities and 
exercises to learn English. Through this website the students can learn the four English skills; listening, speaking, reading, and writing and as well as the English components such as: grammar, vocabulary, and pronunciation. This website provides some beneficial activities for students to learn pronunciation autonomously. They can download the passage and the recording. Besides, they can choose the theme (business English, environment, education, health, issues, lifestyle, people/gossip/entertainment, technology, and world new), level (zero to six), and reading speed (slowest, slower, medium, faster, and fastest).

However, the software and material which is designed for teaching learning is not always appropriate to the applicable curriculum nowadays (Gremmo \& Riley, 1995 cited in Hayta \& Yaprak, 2013). Thus, the teacher's instruction and guidance were still required to implement autonomous learning in learning process. Therefore, in this study the students obtained not only autonomous learning by utilizing breakingnewsenglish.com but also conventional learning.

Some previous studies have been conducted by researchers. One of them is Tsubota, et al. (2004), he analyzed the use of speech recognition system as mean of autonomous learning to improve the students' pronunciation performance. The subjects were 40 students from Kyoto University, Japan. They practiced pronunciation using that tool on four meetings in one semester. The result revealed that the number of the students' pronunciation mistakes which is recorded on that tool significantly decreased after implementing autonomous learning by utilizing speech recognition system. It means that speech recognition system as mean of autonomous learning could improve the students' pronunciation performance.

Many studies which utilized speech recognition system as a tool in learning pronunciation autonomously have been done. Thus, in this study, the researcher tried to utilize different tool to help the students learn pronunciation autonomously. The researcher utilized breakingnewsenglish.com to learn pronunciation autonomously.

\section{METHOD}

This study used a descriptive qualitative design since the data were words or sentences (Moleong, 2016). The subjects were thirteen students of Guidance and Counseling department from the second batch. The researcher chose them because they assumed that the students from the second batch were a fresh graduate so that their English skill was still good. The sources of this study were the students' pronunciation performance and the questionnaires. The data were the students' voice record reading the text from a pronunciation test and the students' response on the implementation of autonomous learning in learning English pronunciation. This study used English pronunciation test and questionnaire as the instrument.

The procedures of collecting data were first, asking permission to the head of Guidance and Counseling department and arranged the basic materials for learning English pronunciation. Second, the researcher designed a rubric of pronunciation performance assessment and a questionnaire. Third, the researcher gave explanation about the basic of English pronunciation materials to the students and how to implement autonomous learning in learning pronunciation by utilizing breakingnewsenglish.com website. Fourth, the students were invited to Guidance and Counseling laboratory and they practiced learning pronunciation by 
utilizing that website. The students were allowed to play the audio as many as possible. While listening to the audio, they noticed how a native speaker pronouncing a word or sentence from the text they chose before and especially the articulation, word endings, word stress, intonation, rhythm, and word linking. The last, they recorded their voice reading the text followed by answering some questions from the questionnaire. The technique of collecting data was observation, field notes, documentation, interview, voice record, and questionnaire.

After the data were collected, it was analyzed descriptively. The data obtained from the students' pronunciation performance were analyzed descriptively based on the rubric of English pronunciation performance assessment. The researcher was assisted by a pronunciation lecturer and a native speaker from America to triangulate the data. The data obtained from the questionnaire were also analyzed descriptively.

\section{FINDINGS AND DISCUSSION}

The result of the implementation of autonomous learning in learning pronunciation which is from the students' pronunciation performance can be seen on the following chart.

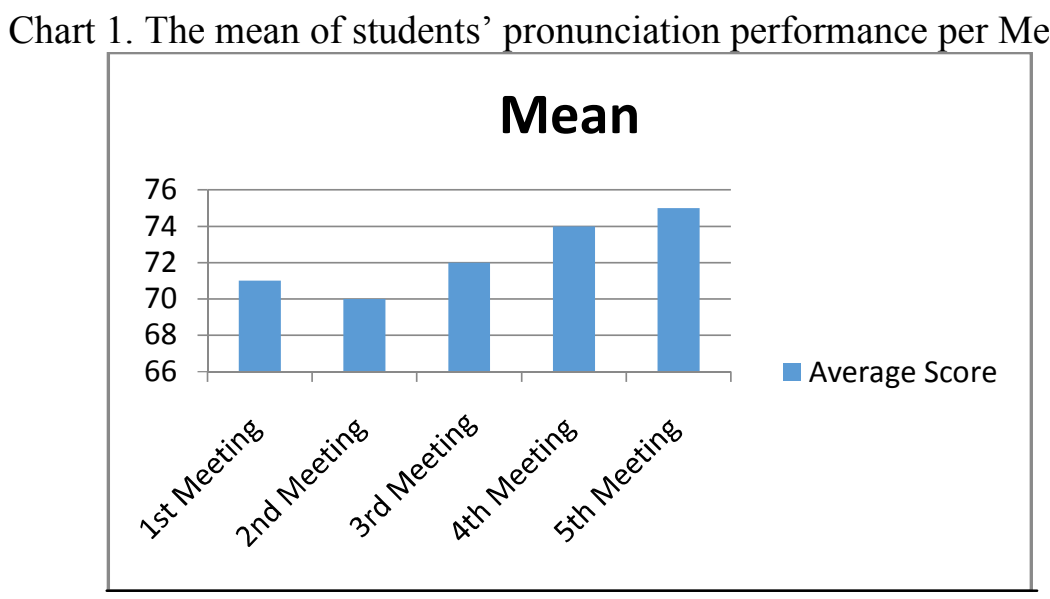

Based on the chart 1 above, it can be seen that there is an improvement on the students' pronunciation performance per meeting. The students' pronunciation performance was increased on the last meeting. It means that autonomous learning can be as an alternative strategy in learning English pronunciation. This result supports the study done by Tsubota, et al. (2004). However, there is a decreasing average on the second meeting. The researcher assumed that it was because of the time in collecting the data. The second data were collected after the students got a lecture so that they felt tired, sleepy, and did not have high motivation. Finally, they could not totally focus on learning pronunciation. Meanwhile, others meeting the data were collected in the morning so that they could totally focus and had a strong motivation in learning pronunciation.

Meanwhile, the result of analyzing the questionnaires revealed that all students were glad and enjoying learning pronunciation autonomously by utilizing breakingnewsenglish.com which provided a lot of activities for learning 
pronunciation. They were also delighted to be able to have a precise model for learning pronunciation because the audio they got from this website was native speaker. They also said this website was really helpful for them in learning the great and precise pronunciation by listening, noticing, and imitating the way of native speaker pronouncing word by word and sentence by sentence in English precisely. Besides, they said that they were glad because they were able to choose the reading speed they want and they were able to play the audio as many as they want. From this response, it can be said that the students' response on the implementation of autonomous learning in learning pronunciation was great or positive.

Chart 2. Favorite Theme Chosen by the Students

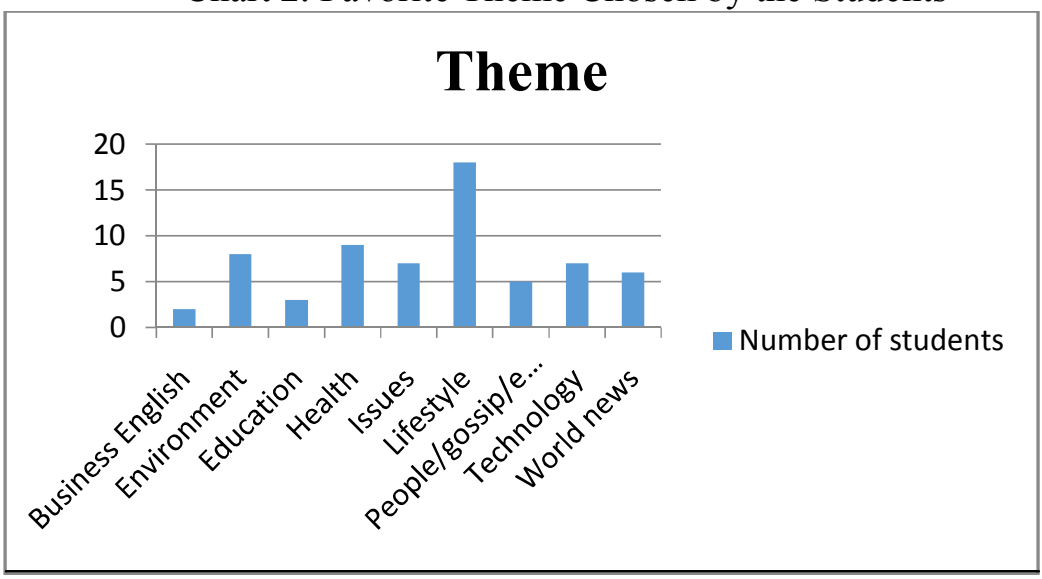

From chart 2 above, it can be seen that the favorite theme chosen by the students was lifestyle. The researcher assumed it was because most subjects of this study were approximately the eighteen-students; they are mostly teenagers so that they prefer reading something about lifestyle.

Chart 3. Favorite Level Chosen by the Students

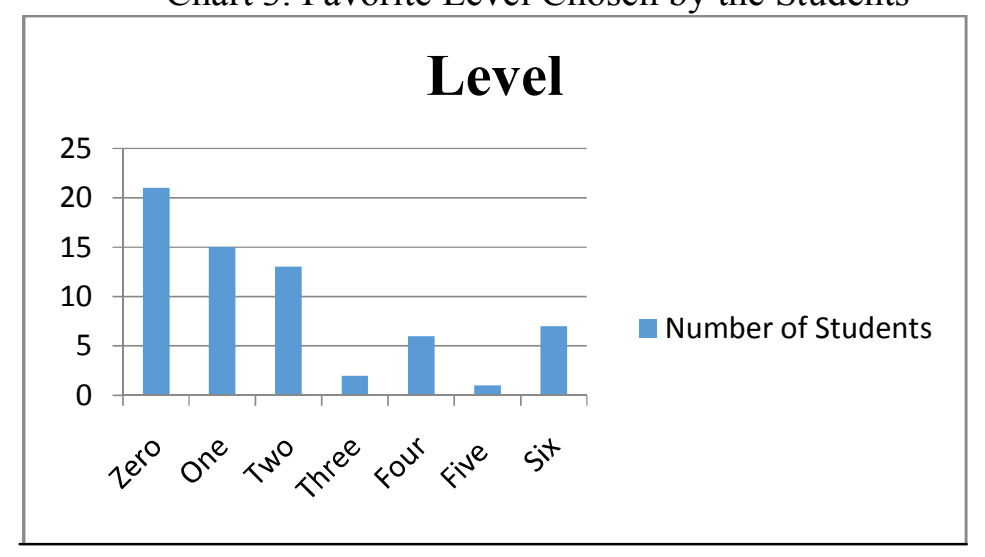

Data on chart 3 above shows the level chosen by the students. The different levels here means that the higher level chosen by the students, the more number of words and the higher level of vocabulary the text is. From chart 3 above, it can be concluded that the favorite level chosen by the students is zero. 
After taking the fourth data, the researcher was wondering why most students chose zero level in every meeting or observation conducted. Therefore, she thought that it required to do interview to know more about the reason. The result of an informal interview conducted by the researcher revealed that the reason of why most students chose zero level was they said that they chose the lowest level because they thought zero level is easier and safer for them; the number of words would be fewer and the level of vocabulary would be lower so that they would finished reading the text faster and easier. The researcher assumed that most students did not have a high confidence in learning English pronunciation. The possible reason was they were ashamed and afraid of making some errors or mistakes.

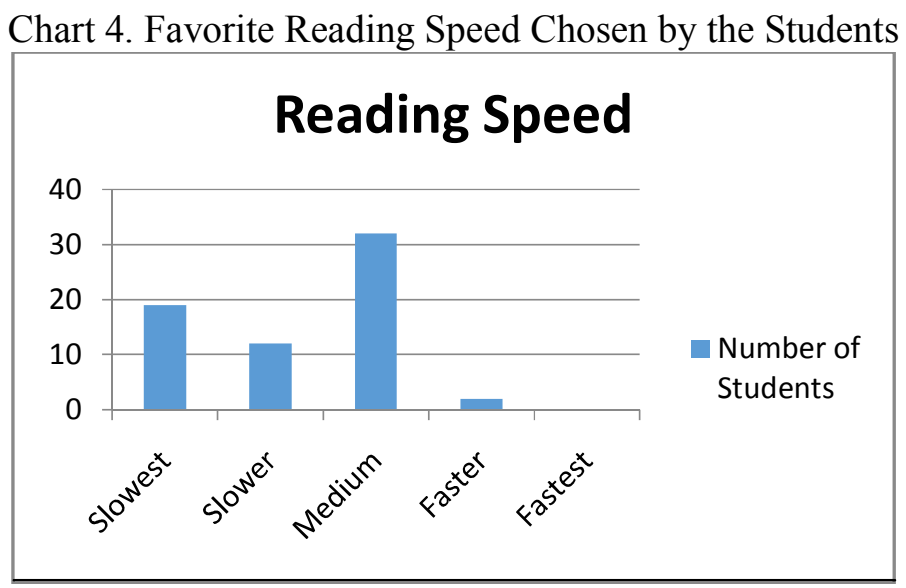

Data on chart 4 shows that favorite reading speed chosen by the students was medium. On the first observation, there were six students from thirteen students who were the subject of this study chose slowest speed and on the next observation, there were five students chose slowest speed. However, on the third, fourth, and fifth observation, most students chose medium speed. It was probably, on the first and the second observation, the students still tried to adapt and observe carefully how a native speaker pronounces English word by word. Meanwhile, on the third, fourth, and fifth observation, they started to be accustomed to listen how a native speaker pronounces English word by word so that most students did not choose slowest speed but they chose medium speed.

Chart 5. Frequency of playing the audio

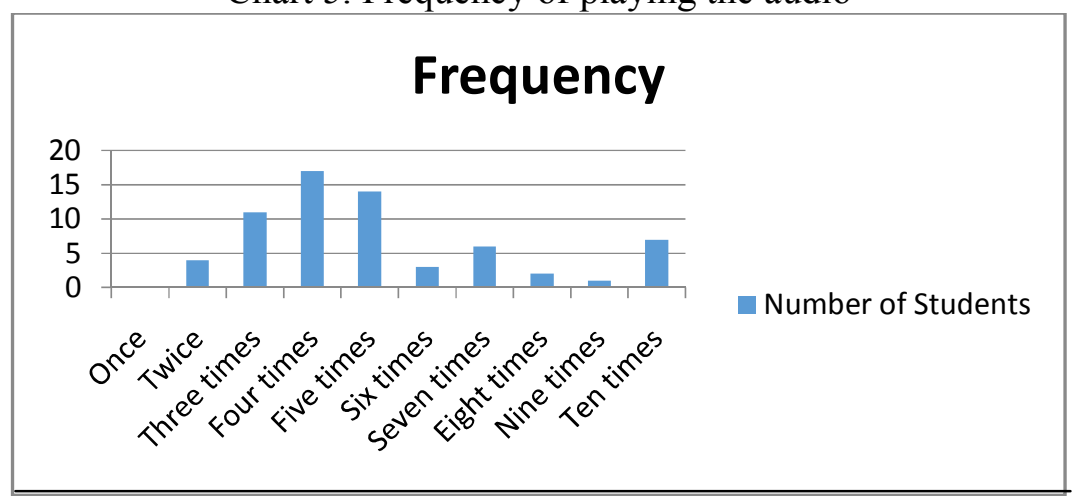


It can be seen from chart 5 above that there were seventeen students who played the audio four times, fourteen students played it five times, and eleven students played it three times before recording their voice. It means that the students mostly played the audio four times before they took a record their voice reading the text they had chosen.

To analyze the impact of the implementation of autonomous learning in learning English pronunciation, it can be seen from the changing of each student's pronunciation performance. The number of the subjects is 13 students. The following are the result of each student's pronunciation performance from the first observation or meeting until the last or the fifth observation.

The changing of the pronunciation performance of student 1 was unstable from the first meeting until the last meeting. On the first meeting, the student's 1 pronunciation performance was 70 but on the second and the third meeting, her performance was decreased. From the researcher's note when data were collected, student 1 looked tired and sleepy. Therefore, the researcher assumed that student's 1 performance was decreased because student 1 was sleepy and tired so that she could not focus and did not have a high motivation in learning. Meanwhile, on the fourth and the fifth meeting, student's 1 score was increased. Inter-rater 1 and 2 gave a note that the weaknesses of student 1 were on word endings, word stress, and word linking.

The pronunciation performance of student 2 on the first and second meeting did not change. However, on the third meeting, her pronunciation performance was increased from 70 to 72 and on the last meeting, her performance was also increased. It shows that the implementation of autonomous learning in learning pronunciation gave a positive impact on student 2. From the researcher's note when observation was conducted, student 2 looked exited and enjoying learning pronunciation by utilizing breakingnewsenglish.com autonomously so that her performance was increased. Inter-rater 1 and 2 said that student's 2 weaknesses were on word endings and word stress.

The pronunciation performance of student 3 was getting better from the first, second, and third meeting. However, on the fifth meeting, it was significantly decreased compared on the fourth meeting. The researcher interviewed her and she said that on the last meeting she got tired so that she was in a hurry when recording her voice. Inter-rater 1 and 2 gave a note for her; they said that her weaknesses were on word endings, intonation, and articulation.

The pronunciation performance of student 4 was increased from the first meeting to the second meeting. On the second, third, and fourth meeting, the performance was stable; no changing. However, on the last meeting, her performance was slightly decreased from 70 to 66 . The researcher tried to find the causes by interviewing her. Student 4 said that she got fever when the fifth meeting was conducted so that she could not focus on learning. Her weaknesses were on word endings and word stress.

The pronunciation performance of student 5 changed unstably from the first meeting to the last meeting. His performance was slight increased on the second meeting while on the third and fourth meeting, it was slightly decreased. It was probably because he was in a hurry for going to his work; two of the subjects of this study had a part time job. However, his pronunciation performance was 
increased on the last meeting. Inter-rater 1 and 2 said that his weaknesses were merely on word endings.

The pronunciation performance of student 6 was slightly decreased on the second meeting from 73 to 71 and on the third and the fourth meeting his performance was slightly decreased as well from 71 to 70 . Meanwhile, on the fifth meeting, his pronunciation performance was significantly increased from 70 to 87 . Student 6 always looked serious and exited with this learning strategy. His weaknesses were slightly on word endings, word stress, and intonation.

The changing of the pronunciation performance of student 7 was not stable from the first meeting to the last meeting. On the first meeting she got 65 while on the second and the third meeting her performance was decreased to be 63 and 60 . It was probably because the second observation was conducted after the students got a lecture, all students felt tired, sleepy, and hungry and finally most of the students' score were decreased. However, on the fourth and the fifth meeting, it was significantly increased to be 71 . Her weaknesses were on articulation, intonation, and slightly on word linking.

The pronunciation performance of student 8 was unstable. It was slightly decreased on the second meeting from 70 to 69 and on the third meeting, her score was 60. Meanwhile, on the fourth meeting her performance was increased significantly to be 79 but on the other hand, it was significantly decreased on the last meeting to be 66. Based on the researcher's note, when observation was conducted, student 8 is a shy and unconfident girl. One of observers sat down close to her when she recorded her voice on the last meeting. Therefore, she told to the researcher that she was nervous and shy when one of observers got closer to her so that she was in a hurry in recording her voice. Her weaknesses were on articulation, intonation, and word stress.

The pronunciation performance of student 9 was amazing. Her scores were very good and the changing of her scores was increased in each meeting. Form the observer's note; she always looked exited, happy, serious, and enjoying learning pronunciation autonomously by utilizing breakingnewsenglish.com. However, her score was slightly decreased on the second meeting because she said that she was hungry and tired after getting a lecture from 8 o'clock to 12 o'clock so that she could not focus on learning. Her weaknesses were on word endings, especially on the final $-\mathrm{s}$ of plural form. It is often occurred on Indonesian students because Indonesian language does not have a sound like the final $-\mathrm{s}$ of plural form.

The pronunciation performance of student 10 was increased in each meeting. Her performance was significantly increased from the first meeting to the last meeting; it was from 71 to 82 . She always looked exited and enthusiastic in learning pronunciation by utilizing breakingnewsenglish.com. She got difficulty in word endings, especially on the final $-\mathrm{s}$ of the plural form and final -ed of the past form. It was normally occurred because Indonesian language does not have final $-\mathrm{s}$ and final $-\mathrm{ed}$.

The pronunciation performance of student 11 was significantly increased from the first meeting until the last meeting; it was from 69 to 81 . It shows that this learning strategy gave a good impact on student 11. However, her pronunciation performance score was decreased on the second meeting because she felt tired and hungry after having a lecture in the morning. Her weaknesses 
were on articulation, especially on vowel sound and word endings on the final $-\mathrm{s}$ of the plural form.

The pronunciation performance of student 12 was significantly increased in each meeting. On the first meeting, his score was 70 and the last meeting she got 78. His seriousness and enthusiasm gave a positive and great result for his pronunciation score. However, there were some weaknesses he had; they are on word endings of the final $-\mathrm{s}$ and -ed, slightly on articulation; especially vowel, intonation, and word stress. His first language interferes his pronunciation ability because Indonesian language does not have final $-\mathrm{s}$ and $-\mathrm{ed}$ which show plural and past form.

The pronunciation performance student 13 was increased well in each meeting. The first meeting he got 70 and the last meeting, he got 78 . However, his performance was decreased on the fourth meeting. It was because he was in a hurry when he recorded his voice; he wanted to go to his work soon. Therefore, he could not focus on learning pronunciation autonomously. His weaknesses were on word endings, especially on the final -s and -ed and slightly on word stress.

\section{CONCLUSION}

From the result and discussion above, it can be concluded that the implementation of autonomous learning in learning pronunciation was good. It can be seen from the average of the students' pronunciation performance score from the first meeting to the last meeting was significantly increased. All students were enthusiastic, exited, and enjoying this learning strategy. They said that breakingnewsenglish.com was good and helpful for them in learning English pronunciation well and correctly because they could get the right model; the audio or recording from that website was from a native speaker. The favorite theme chosen by the students was lifestyle, the favorite level was zero, the favorite reading speed was medium, and the frequency of playing the audio chosen by the students was four times.

Besides, the score of each student shows that autonomous learning with the help of breakingnewsenglish.com in learning English pronunciation gave a positive and good impact on the students' pronunciation performance score. In summary, breakingnewsenglish.com as a website which assists the students in learning English pronunciation autonomously can be as an alternative strategy in learning pronunciation. One thing recommended by the researcher for the future studies was do not take the data when the students were tired, sleepy, hungry because they will not be able to concentrate and focus on learning.

\section{REFERENCES}

Burns, A. (2003). Clearly speaking: pronunciation in action for teachers. National Center for English Language Teaching and Research, Macquaire University, Sydney NSW 2109

Gilakjani A. P. (2016). English pronunciation instruction: A literature review. International Journal of Research in English Education. 1(1). 1-6. Diunduh dari https://ijreeonline.com/article-1-21-en.pdf 
Hayta, F. \& Yaprak, Z. (2013). Learner autonomy and computer technology as a facilitator of autonomous language learning. Journal of Educational and Instructional Studies in the World. 3(2). 57-63. Diunduh dari http://www.wjeis.org/FileUpload/ds217232/File/09_a_fatma_hayta_zeyn ep_yaprak.pdf

Johar, R. (2015). Model-model pembelajaran berdasarkan kurikulum 2013 untuk mengembangkan matematis dan karakter siswa. Diunduh dari www.rp2u.unsyiah.ac.id/index.php/welcome/prosesDownload/1133/5

Morley, J. (1991). The pronunciation component in teaching English to speakers of other languages, TESOL Quarterly, 25(1), 51-74. Diunduh dari https://deepblue.lib.umich.edu/bitstream/handle/2027.42/90128/3586981.p df? sequence $=1$

Pratiwi, M. R. (2010). Improving Pronunciation Ability Using Cartoon Films. Diunduh dari https://core.ac.uk/download/files/478/12346825.pdf

Riadi, A. (2013). Students' Problems in Pronouncing Short and Long English Vowels. Pontianak: Universitas Tanjungpura. Retrieved from

https://www.google.co.id/url?sa=t\&rct=j\&q=\&esrc=s\&source=web\&cd=1\&cad=r ja\&uact $=8 \& v e d=0$ ahUKEwi596_7qZfXAhXJv48KHfOuCsQFggoMAA\&url=http\%3A\%2F\%2Fjurnal.untan.ac.id\%2Findex.php\%2 Fjpdpb\%2Farticle\%2Fdownload\%2F4299\%2F4337\&usg=AOvVaw01Oon VOhqC04vmxKFwwl7V

Tsubota, Y., dkk. (2004). Proceeding dari InSTIL/ICALL2004 - NLP and Speech Technologies in Advanced Language Learning Systems. Di unduh dari http://www.iscaspeech.org/archive_open/archive_papers/icall2004/iic4_033.pdf

Wang, J. (2010). How to develop college students' autonomous English learning skills-Take reading course in joint-program in HCFT as an example. Journal of English Language Teaching. 3(3). 221-228. Diunduh dari www.ccsenet.org/elt 